\title{
UNUSUAL FORMS OF TRACHEOBRONCHIAL COMPRESSION IN INFANTS WITH CONGENITAL HEART DISEASE
}

\author{
M. C. Robotin, MBBS, FRACS \\ J. Bruniaux, MD \\ A. Serraf, MD \\ M. Sousa Uva, MD \\ R. Roussin, MD \\ F. Lacour-Gayet, MD \\ C. Planché, MD
}

Three groups of unusual forms of tracheobronchial compression caused by vascular anomalies are presented. Three patients had an encircling right aortic arch with a left-sided descending aorta and ligamentum arteriosum (group 1), two patients had airway compression caused by a pincer effect between a malposed and enlarged ascending aorta and the descending aorta (group 2), and three patients had airway compression after an arterial switch operation for transposition of the great arteries (group 3). Symptoms developed in all patients before the age of 4 months, and six of them had multiple failed attempts at extubation before the surgical intervention directed at relieving the airway compression. Fiberoptic endoscopy was used in all patients as a first-line diagnostic tool and was $100 \%$ accurate in establishing the diagnosis. The operations performed were aortic uncrossing in group 1, dissection and aortopexy of the right or left main bronchus in group 2, and dissection of the left main bronchus and lysis of adhesions in group 3 . In group 1 there was one early death, resulting from aspiration, and one late death 4 years later, resulting from an unrelated cause. In this group, bronchomalacia was noted after the operation and resolved gradually in the year after the intervention. In group 2, one patient died of an aortobronchial fistula after placement of a bronchial stent. Group 3 patients had good postoperative results. Two of them are completely symptom-free and one has residual bronchomalacia and may need placement of a bronchial stent. ( $J$ Thorac Cardiovasc Surg 1996;112:415-23)
$\mathrm{T}_{\mathrm{g}}^{\mathrm{r}}$ racheobronchial compression in infants with congenital heart disease has been reported in many contexts, including that of vascular rings and slings-with or without associated intracardiac disease-large left-to-right shunts, anomalous origin of a coronary artery from the pulmonary artery, or the iatrogenic variety following repair of an aortic arch interruption, aortic coarctation, or construction of systemic-pulmonary artery shunts. ${ }^{1-4}$ Our experience consists of more than 500 infants and children undergoing operations for symptomatic tracheobronchial compression belonging to all of these

From Marie Lannelongue Hospital, Paris, France.

Received for publication August 31, 1995; revisions requested Oct. 27, 1995; revisions received Dec. 11, 1995; accepted for publication Jan. 18, 1996.

Address for reprints: Claude Planché, MD, Department of Pediatric Cardiac Surgery, Marie Lannelongue Hospital, 133, Avenue de la Résistance, 92350 Le Plessis-Robinson, France.

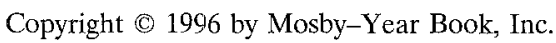

$0022-5223 / 96 \$ 5.00+0 \quad \mathbf{1 2 / 1 / 7 2 1 2 4}$ groups. For the purpose of this report, we have selected eight patients who had unusual compressive mechanisms, as well as other features that set them apart. They all had symptoms before 4 months of age. Six patients required preoperative tracheal intubation and had repeated, unsuccessful attempts to be weaned from mechanical ventilation.

\section{Patients and methods}

The clinical records of eight patients were retrospectively reviewed and the following data were recorded for each patient: sex, age and weight at the onset of symptoms, need for preoperative intubation, type of disease, age at the first and subsequent operations and the nature of these operations, postoperative complications, duration of postoperative ventilatory support, hospital stay, and length of follow-up.

Three groups of patients were identified (Table I): group 1 , consisting of three patients with right-sided aortic arch with left-sided descending aorta and ligamentum arteriosum (also described as circumflex aorta); group 2, comprising two patients in whom the trachea was compressed between an enlarged aortic root, displaced toward the right of the mediastinum and the descending aorta; 
Table I. Characteristics of patients

\begin{tabular}{|c|c|c|c|c|c|c|}
\hline $\begin{array}{l}\text { Patient } \\
\text { No. }\end{array}$ & Anomalies & $\begin{array}{l}\text { Age at onset } \\
\text { of symptoms }\end{array}$ & $\begin{array}{l}\text { Preop. } \\
\text { intubation }\end{array}$ & $\begin{array}{l}\text { Age and weight } \\
\text { at operation }\end{array}$ & $\begin{array}{l}\text { Length of postop. } \\
\text { intubation }\end{array}$ & Outcome \\
\hline \multicolumn{7}{|l|}{ Group 1} \\
\hline 1. & $\mathrm{CA}, \mathrm{VSD}$ & $3 \mathrm{wk}$ & Yes & $5 \mathrm{mo}, 5.4 \mathrm{~kg}$ & 4 days & Died at $1 \mathrm{mo}$ \\
\hline 2 & CA, VSD & $6 \mathrm{wk}$ & Yes & $15 \mathrm{wk}, 7.1 \mathrm{~kg}$ & 15 days & Lost to follow-up after $2 \mathrm{yr}$ \\
\hline 3 & $\mathrm{CA}, \mathrm{VSD}, \mathrm{ASD}$ & 2 wk & Yes & $14 \mathrm{wk}, 4.8 \mathrm{~kg}$ & $11 \mathrm{wk}$ & Died at $4 \mathrm{yr}$ \\
\hline \multicolumn{7}{|c|}{ Group 2} \\
\hline 4 & TOF, malposed Asc Ao & 1 day & Yes & $12 \mathrm{wk}, 2.5 \mathrm{~kg}$ & $6 \mathrm{wk}$ & $\mathrm{A} \& \mathrm{~W}$ at $9 \mathrm{yr}$ \\
\hline 5 & $\begin{array}{l}\text { Multiple VSDs, RPA agenesis, } \\
\text { malposed Asc Ao }\end{array}$ & 3 days & Yes & $4 \mathrm{wk}, 3.9 \mathrm{~kg}$ & $10 \mathrm{wk}$ & Died at $10 \mathrm{wk}$ \\
\hline \multicolumn{7}{|l|}{ Group 3} \\
\hline 6 & TGA + IVS & $5 w k$ & Yes & $8 \mathrm{wk}, 5.2 \mathrm{~kg}$ & 8 days & $A \& W$ at $6 \mathrm{yr}$ \\
\hline 7 & TGA + IVS & $16 \mathrm{wk}$ & No & $13 \mathrm{mo}, 10.7 \mathrm{~kg}$ & 1 day & A \& W at 9 mo \\
\hline 8 & $\mathrm{TGA}+\mathrm{IVS}$ & $6 \mathrm{wk}$ & No & $14 \mathrm{wk}, 4.9 \mathrm{~kg}$ & 3 days & A \& W at $6 \mathrm{mo}$ \\
\hline
\end{tabular}

$C A$, Circumflex aorta; $V S D$, ventricular septal defect; $A S D$, atrial septal defect; $T O F$, tetralogy of Fallot; $A s c A O$, ascending aorta; $R P A$, right pulmonary artery; $T G A$, transposition of great arteries; $I V S$, intact ventricular septum; $A \& W$, alive and well.

and group 3, comprising three patients who had tracheobronchial compression as a consequence of an arterial switch operation for transposition of the great arteries.

Group 1. Group 1 patients have been the subject of two reports published in the French literature. ${ }^{5,6}$ The anatomy was defined as a right aortic arch with retroesophageal aortic segment and a left-sided descending aorta and ligamentum arteriosum (circumflex aorta), as described by Langlois and associates ${ }^{7}$ and Knight and Edwards. ${ }^{8}$ In this anomaly, the single aortic arch passes over the right main bronchus to the right of the trachea and esophagus. It then takes a retroesophageal course to gain the left side of the mediastinum, where it joins the left-sided descending aorta. At this point, a diverticulum marks the origin of the left subclavian artery, coursing cephalad, and of the ductus arteriosus, coursing caudad, to join the left pulmonary artery (Fig. 1). This arrangement creates a vascular ring, formed by the right-sided aortic arch to the right, its retroesophageal segment posteriorly, the ductus arteriosus to the left, and the bifurcation of the main pulmonary artery anteriorly.

Unlike most other patients with this anomaly described in the literature, all three had coexistent intracardiac disease involving ventricular septal defects in all and a large atrial septal defect as well in patient 3 . They all had severe symptoms early in life and needed a left thoracotomy and interruption of the vascular ring at the level of the ductus arteriosus at the ages of 7,8 , and 10 weeks, respectively. Despite careful mobilization of the divided ends of the duct, the symptoms of compression persisted, making extubation impossible. Inasmuch as patient 2 had a sizable perimembranous ventricular septal defect (pulmonary-systemic flow ratio of 2:1), the defect was closed subsequently, on the assumption that it could have contributed to the airway symptoms. Aortopexy was performed at the same time. Unfortunately, in all of these patients the postoperative bronchoscopic examination showed again the same extrinsic, pulsatile compression of the distal trachea and right main bronchus caused by the ascending aorta. Faced with this therapeutic dilemma, we decided to attempt a novel solution, that of an "aortic uncrossing." The aortic arch was mobilized, divided, and brought in front of the tracheobronchial tree, then reanastomosed end to side to the lateral aspect of the ascending aorta (Fig. 2). The ages of these patients at operation were 20,15 , and 14 weeks, respectively.

Operative procedure. Good exposure was afforded by a midline sternotomy incision, although in one patient a bilateral anterior thoracotomy extending across the sternum was used. The arch vessels were dissected completely. The right subclavian artery, which in this condition arises as the third branch of the aortic arch, was divided to allow better arch mobilization. The arch was carefully dissected from the posterior aspect of the trachea and esophagus, because at this point it was intimately adherent to both. The descending aorta was approached through the left side of the mediastinum, and here difficulties may arise because of the posterior location of the aorta and the postoperative adhesions caused by the previous division of the patent ductus arteriosus. Cardiopulmonary bypass was instituted by cannulating the ascending aorta and the right atrium. The aortic uncrossing was performed with the aid of hypothermic circulatory arrest for 49, 37, and 54 minutes, respectively. This included the time needed to close the atrial and ventricular septal defects in patient 3 . The aortic arch was transected just distal to the origin of the right subclavian artery, and dissection of the retroesophageal aorta allowed its uncrossing and reanastomosis end to side to the ascending aorta, in front of the tracheoesophageal axis.

Extubation was possible 4 and 15 days later in the first two patients but was delayed by 11 weeks in the last patient, who had severe bronchomalacia.

Patient 1 died 1 month after the operation after an episode of aspiration, possibly related to recurrent laryngeal nerve injury during the last intervention. The postmortem examination showed that the aortic repair was of normal caliber. No residual bronchial compression was present, but bronchomalacia of the left main bronchus was noted. A perimembranous ventricular septal defect, 2 by $4 \mathrm{~mm}$, considered too small to require closure during the last operative intervention, was noted.

Patients 2 and 3 still had occasional stridor in the year that followed their operations. They both had a second 


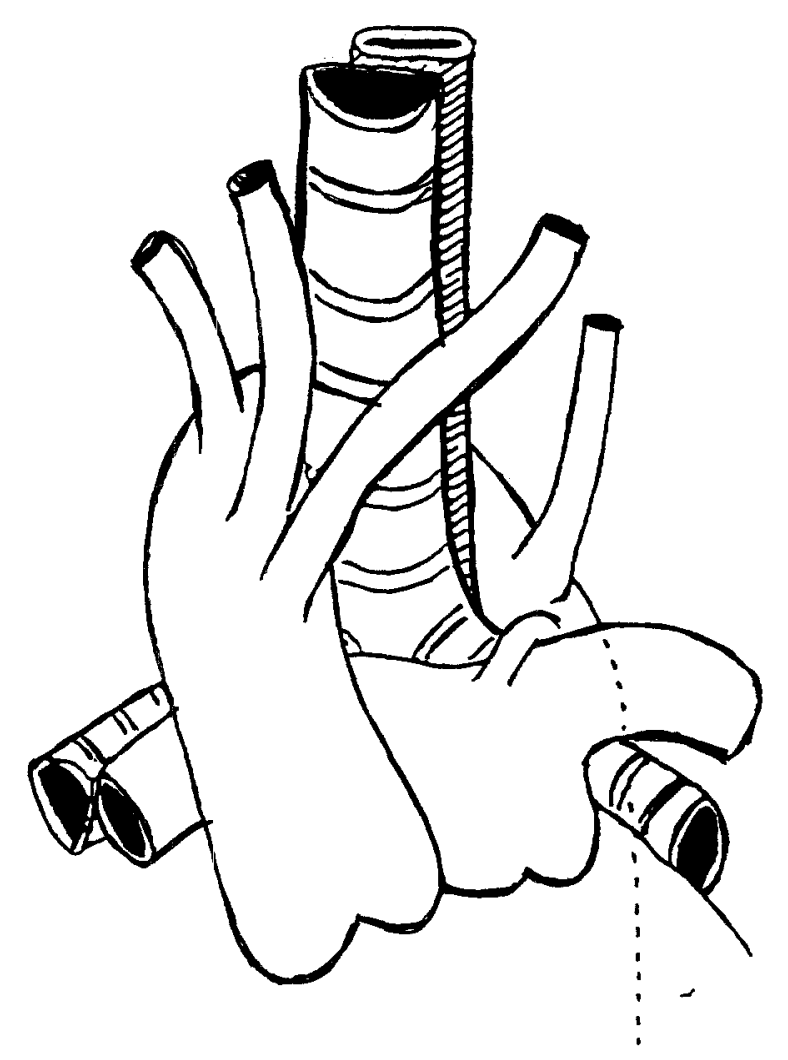

Fig. 1. The vascular anatomy present in circumflex aortas: the right-sided aortic arch passes over the right main bronchus, then takes a retroesophageal course and joins the left-sided descending aorta.

bronchoscopic examination, which confirmed the disappearance of the vascular compression. Digital subtraction angiography of the aortic arch confirmed the accuracy of the vascular repair. Patient 2 was lost to follow-up after his adoption 2 years after his operation, at which time he was free of symptoms referable to airway compression. Patient 3 died 4 years later of an unrelated cause.

Group 2. Patient 4 was born at 29 weeks' gestation, with a birth weight of $1000 \mathrm{gm}$, and required immediate intubation for respiratory distress. On the third day, a heart murmur was heard and an echocardiogram diagnosed tetralogy of Fallot, with a right-sided aortic arch and descending aorta. Repeated attempts at weaning from mechanical ventilation failed, because each was followed by an episode of bronchospasm. When the infant was 10 weeks old, cardiac catheterization and angiocardiography confirmed the echocardiographic findings and outlined a dilated, dextroposed ascending aorta, separated from the right-sided descending aorta by a narrow space, particularly at the level of the right main bronchus. A bronchoscopic examination showed that the right main bronchus was reduced to a slitlike opening. At the age of 3 months, when he weighed $2500 \mathrm{gm}$, he underwent a right thoracotomy. Dissection of the right main bronchus confirmed that the bronchus was "squashed" between the ascending

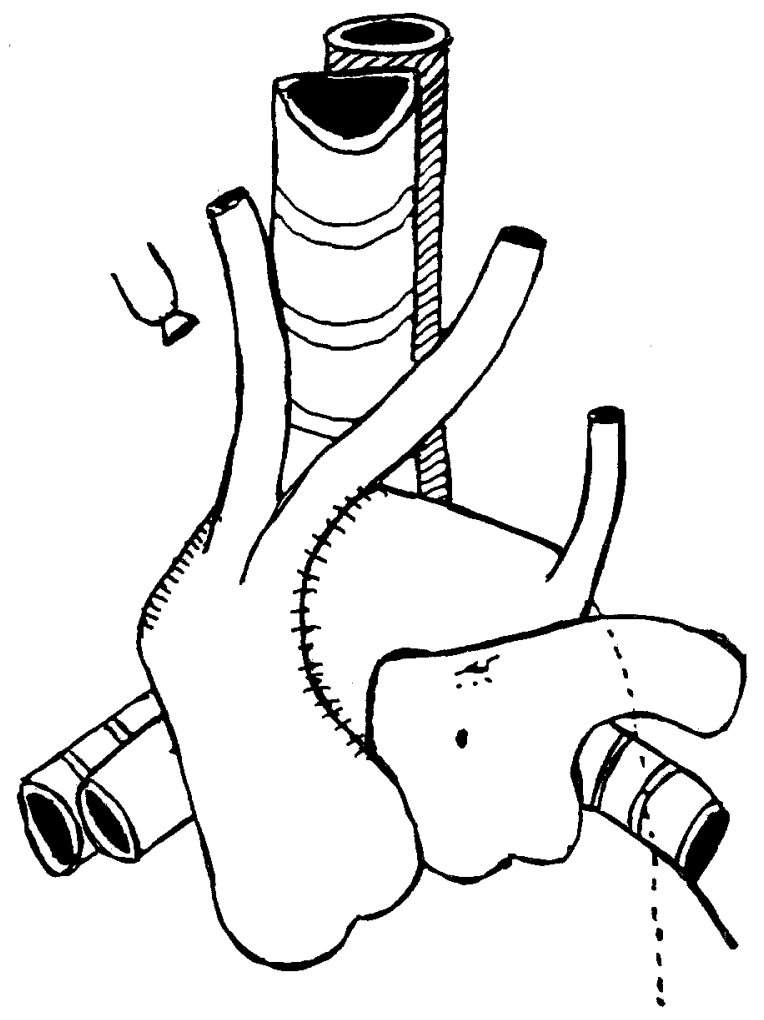

Fig. 2. Schema of the aortic uncrossing procedure. The right subclavian artery is divided. The aortic arch is transected proximal to the origin of the right subclavian artery, mobilized, and reanastomosed to the left side of the ascending aorta and left carotid artery, in front of the trachea.

and descending aorta. Inasmuch as the ascending aorta could not be mobilized enough through this approach, an extensive mobilization of the descending aorta was undertaken, which enabled it to be suspended to the posterior parietal pleura, relieving the compression. A small patent ductus arteriosus, which did not contribute to airway compression, was left intact to enhance pulmonary blood flow in the context of tetralogy of Fallot. A systemicpulmonary artery shunt was not performed, because the oxygen saturation was adequate and there was concern that a shunt might aggravate the compressive symptoms. Postoperative bronchoscopic examination showed relief of the compression and mild bronchomalacia. Prolonged ventilation was needed because of severe bronchopulmonary dysplasia. A tracheostomy was performed and then allowed to close 10 months later, when all respiratory problems had subsided. A one-stage repair of the tetralogy of Fallot was not considered in view of the patient's weight and hypoplastic pulmonary valve ring. The child remained well for the following 2 years, when he underwent an elective correction of the tetralogy of Fallot. He was extubated the following day and had an uncompli- 


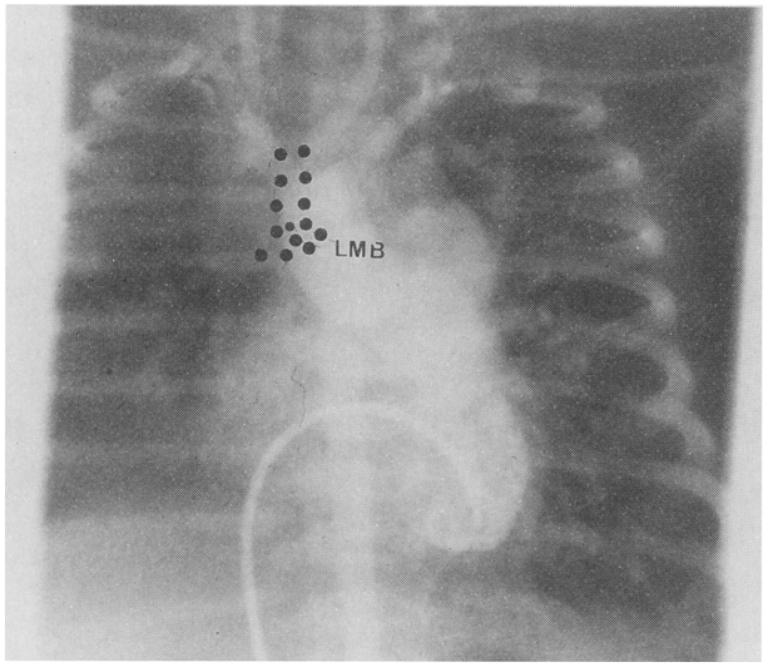

Fig. 3. Left ventricular angiogram in patient 5 (anteroposterior and lateral views), outlining a dilated ascending aorta, displaced posteriorly and to the right. The left main bronchus $(L M B)$ is compressed between the ascending and descending aorta.

cated postoperative course. He remains well 9 years after the initial operation.

Patient 5 was born at 40 weeks' gestation and required tracheal intubation at 3 days of age for respiratory distress. Cardiac catheterization and angiocardiography performed 5 days later showed a perimembranous as well as a muscular ventricular septal defect, with isosystemic pressures in the pulmonary artery, as well as absence of the right pulmonary artery (Fig. 3). The right lung was hypoplastic and the ascending aorta was enlarged and shifted to the right side of the mediastinum. Bronchoscopic examination showed the left main bronchus to be compressed by a pulsatile element in an anteroposterior plane. The right bronchus was patent. Repeated episodes of hypercapnia necessitated use of high ventilatory pressures, which in turn caused a large bronchopleural fistula to develop in the hypoplastic right lung. Repeated attempts at extubation failed, and at the age of 4 weeks she had a left thoracotomy to free the compressed left main bronchus. A small patent ductus arteriosus was divided to gain access to the bronchus, which was extensively mobilized. It was evident that the compression was caused by the large aortic root, but anterior aortopexy was not performed, because the management plan involved closure of the ventricular septal defects in the immediate future. A postoperative bronchoscopic examination showed that the bronchial compression was relieved but that the left bronchus had extensive bronchomalacia. Unfortunately, the intracardiac repair had to be delayed because the right bronchopleural fistula became infected and ultimately necessitated a right pneumonectomy at the age of 10 weeks for control of sepsis. The right lung was completely necrotic and purulent. A second bronchoscopic study 2 months after the original operation showed recurrent left bronchial compression. Because repeated

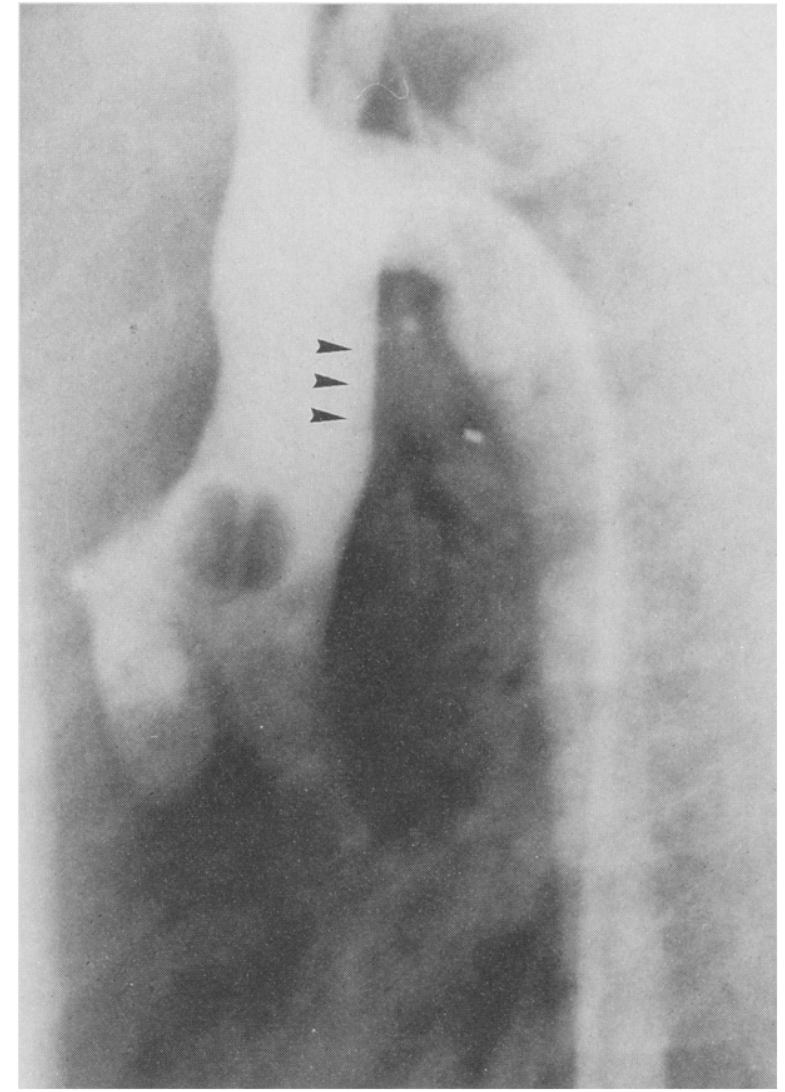

Fig. 4. Arch aortogram in patient 7 , demonstrating the posterior displacement of the ascending aorta after the Lecompte maneuver. However, the space is not sufficiently narrow to alone explain the airway symptoms.

operative interventions seemed unlikely to be successful, a selective left bronchial intubation with a size 4 uncuffed endotracheal tube was performed. Intubation provided immediate improvement in ventilatory mechanics. Unfortunately, 2 weeks later a massive hemoptysis resulted in airway obstruction and death. The postmortem examination showed an aortobronchial fistula caused by compression of the bronchial wall between the bronchial stent from within and the ascending aorta from without.

Group 3. Group 3 consists of three patients in whom symptoms of airway compression developed some time after an arterial switch operation for transposition of the great vessels.

All patients had a simple transposition and in each of them the aorta was situated anterior and to the right of the pulmonary artery. The arterial switch operation was performed at the ages of 11,5 , and 9 days by means of our standard technique, which we have used in more than 800 patients to date. The patent ductus arteriosus was ligated with 3-0 Ti-Cron sutures (Davis \& Geck Div., American Home Products, Danbury, Conn.) and the divided ends were oversewn with 7-0 polypropylene. The Lecompte maneuver was used in all, to bring the neopulmonary artery in front of the neoaorta. The postoperative course 


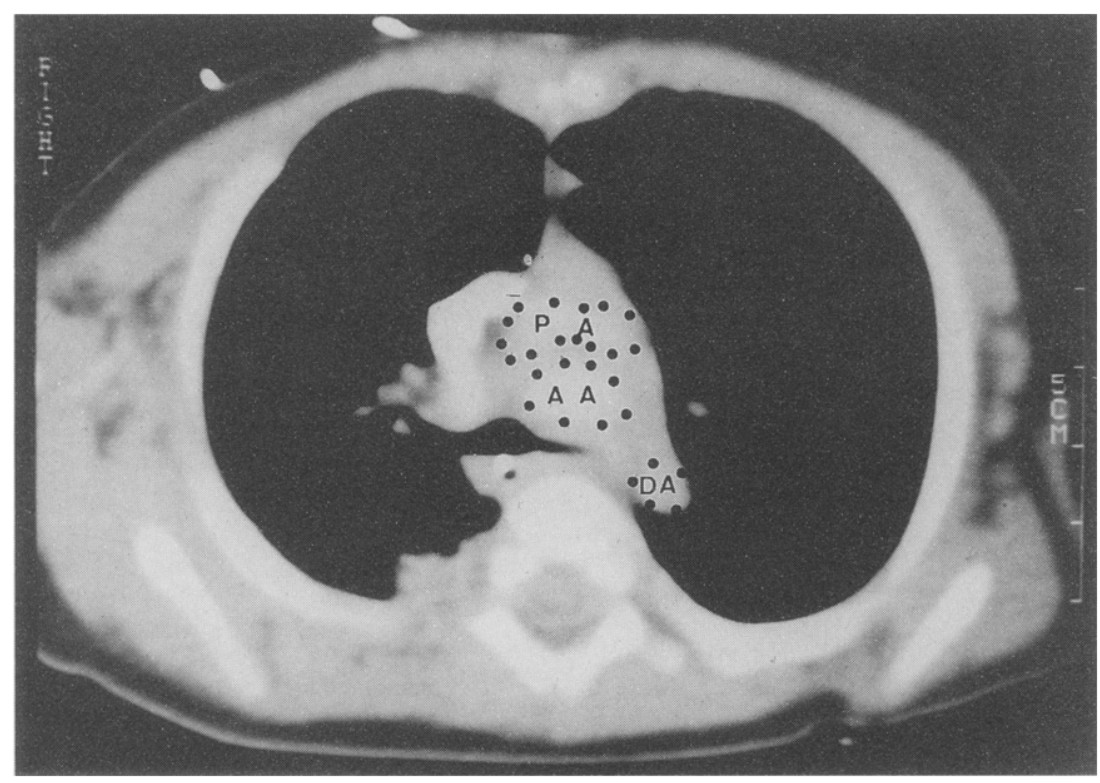

Fig. 5. Thoracic computed tomographic scan with contrast in patient 8 , showing near obliteration of the left main bronchus after an arterial switch operation. $P A$, Pulmonary artery; $A A$, ascending aorta; $D A$, descending aorta.

was uneventful in all and the initial progress after discharge was satisfactory.

At the ages of 5,20, and 4 weeks, respectively, they all had sudden, severe respiratory distress, ranging from severe stridor and wheezing in patient 8 to respiratory arrest mandating emergency endotracheal intubation in patients 6 and 7. The initial diagnosis was bronchiolitis, but this was not supported by the bacterial and viral cultures or by the subsequent clinical course. Extubation was not possible in patient 6 and the clinical condition of patients 7 and 8 remained precarious.

All patients had cardiac catheterization and angiocardiography to elucidate the diagnosis. The coronary anastomoses were free of technical problems, as were the great vessels, with the aorta describing a curve concave anteriorly, as a result of the Lecompte maneuver (Fig. 4). Patient 8 was found to have a large collateral vessel originating from the left subclavian artery and passing to the left hilum anterior to the left bronchus. He also had a computed tonographic scan of the thorax, which showed marked compression of the left main bronchus between the ascending and descending aorta (Fig. 5).

The diagnosis was made with certainty in all three patients by bronchoscopic examination, which demonstrated the pulsatile nature of the vascular compression, affecting the distal trachea and particularly the origin of the left main bronchus, which was slitlike. The obstruction could be traversed without difficulty with the flexible bronchoscope, showing a normal distal bronchial lumen.

At the ages of 8 weeks, 13 months, and 14 weeks, respectively, the patients underwent a left thoracotomy to relieve the bronchial compression. The operative findings were similar in all three cases. The compression appeared to be due to three individual elements situated in three different planes. The aortopulmonary window was occupied by a mass of small, matted lymph nodes, probably a reaction to recurrent bronchial infection. A second plane of dense fibrosis occupied the site of the divided ductus arteriosus; on further mobilization, it became apparent that the posteriorly displaced ascending aorta contributed to the compression on a deeper plane. The collateral vessel crossing the bronchus was divided in patient 8 . Inasmuch as he was the only one of the three whose bronchus remained flattened after the wide dissection, suggesting significant bronchomalacia, anterior and posterior aortopexies were also performed.

Patient 6 had an uncomplicated postoperative course, remains symptom-free, and has normal bronchoscopic findings 6 years later.

Patient 7 was extubated on return to the intensive care unit and had no postoperative problems. A bronchoscopic study 3 months later showed relief of the compression and mild residual bronchomalacia, and he remains free of symptoms 9 months after the intervention.

Patient 8 had a bronchoscopic study in the immediate postoperative period, which showed no residual compression but significant bronchomalacia of the proximal left bronchus. Inasmuch as he was successfully extubated 3 days later, however, a bronchial stent was not considered, because in our experience the bronchomalacia always improved over the following months. His clinical condition did indeed improve, but he still has noticeable wheezing on effort, and a second bronchoscopic examination 5 months later showed the bronchomalacia to be 
unchanged. If improvement does not continue, the placement of a bronchial stent will be considered.

\section{Discussion}

Vascular anomalies causing tracheobronchial compression were observed as early as 1737 , when Hommel $^{9}$ described a case of double aortic arch. Surgical treatment of a double aortic arch was first performed by Gross ${ }^{10}$ in 1945 . In the same report he described the anatomic features that we observed in our first group of patients: a right-sided aortic arch, retroesophageal in location, with a left-sided ligamentum arteriosum and descending aorta. In 1948 Edwards ${ }^{11}$ described the embryologic development of the aortic arches in relation to these anomalies.

Since then, many reports have documented successful resolution of compressive symptoms after division of vascular rings. In $1991 \mathrm{we}^{7}$ reported our own experience with 468 cases.

This report focuses on unusual cases, which did not fall into the expected clinical patterns. We have also described a new form of compression associated with repair of transposition of the great vessels, previously described only as a single case report in the literature. ${ }^{12}$

Patients in groups 1 and 2 required treatment before the age of 6 weeks. They all required preoperative intubation of the trachea for respiratory distress manifested as stridor and wheezing. Repeated attempts at extubation were unsuccessful in all.

Bronchoscopic examination was performed as a first-line diagnostic tool. As pointed out by Binet and Langlois ${ }^{13}$ from our institution, the bronchoscope accurately visualizes the compression and confirms its extrinsic and vascular nature. In these patients, it was $100 \%$ accurate in making the diagnosis.

We acknowledge that bronchoscopic study may be hazardous in inexperienced hands, but we have not had any problems with it and advocate its routine use. ${ }^{14}$ We believe bronchoscopy is safer than tracheography, which Corno and associates ${ }^{15}$ found to be the most useful investigation in their patients with congenital heart disease and coexistent airway obstruction. It also has the advantage that it can be performed at the bedside, avoiding hazardous transfers to remote radiology departments.

We have not used magnetic resonance imaging for diagnostic purposes, but we acknowledge the excellent quality of the imaging afforded by the three-dimensional reconstructions possible with this technique. ${ }^{16}$
The vascular ring described in group 1 (which for brevity we call circumflex aorta, a term introduced by D'Cruz and associates ${ }^{17}$ in 1966) may cause respiratory problems early in life. In the vast majority of cases, division of a vascular ring at the level of the ductus arteriosus suffices for the relief of symptoms. ${ }^{18}$ However, in our three patients, division of the vascular ring combined with mobilization of the divided ends of the ductus was ineffective. Aortopexy is sometimes advocated as an adjunctive operative measure, ${ }^{19}$ but we used it without success in patient 2 .

We have not encountered any reports of patients with this abnormality having severe residual compression after division of the ductus arteriosus, but without a careful bronchoscopic examination it can be difficult to differentiate residual compression from secondary bronchomalacia. For example, in the series reported by Lam and coworkers, ${ }^{20}$ one of the patients with a double aortic arch with a small anterior component could not be extubated after the operation and died later as a consequence of severe respiratory distress. We could speculate that residual compression was the causative mechanism.

The cause of respiratory difficulties in the postoperative period is generally thought to be secondary bronchomalacia, but we believe that this should be a diagnosis of exclusion, because the symptoms of residual compression may be similar. In our three patients, bronchoscopic examination after division of the vascular ring showed the vascular compression to be unrelieved and a new solution had to be found.

A previous report by Domalain and coworkers ${ }^{21}$ described how the symptoms of esophageal compression in an infant with a circumflex aorta were relieved by dissecting the esophagus and uncrossing it behind the vascular ring, which was left undisturbed.

Hellebrand and associates ${ }^{22}$ reported a case in which the retroesophageal aortic segment was long and tortuous. As in our three patients, there was an associated ventricular septal defect, for which banding of the pulmonary artery was performed. At a second operation, a polytetrafluoroethylene graft was interposed between the left common carotid artery and the descending aorta. A direct anastomosis was not performed because of concern this would complicate the future intervention of pulmonary artery debanding and closure of the ventricular septal defect, which was successfully performed 5 years later. The authors contended that future con- 
duit changes would be needed to accommodate for growth.

Although Knight and Edwards ${ }^{8}$ found associated intracardiac lesions to be rare with this type of vascular ring, all our three patients, as well as the patient reported on by Hellebrand's group, had an associated ventricular septal defect. As D'Cruz, ${ }^{17}$ Ergin ${ }^{14}$ and their colleagues commented in their respective series, in this type of vascular ring intracardiac defects may in fact be quite common.

Although Hodorf and coworkers ${ }^{4}$ documented the rapid regression of the signs of obstructive airway disease after closure of large left-to-right shunts, we have not found any improvement in patient 2. Patient 1 did not have closure of the ventricular septal defect, because it was considered too small to warrant surgical attention. Inasmuch as the airway obstruction was demonstrated both bronchoscopically and angiocardiographically to be caused by the aortic arch itself, reduction in size of the pulmonary artery and left atrium would have had little impact on the primary anomaly.

Damage to the left recurrent laryngeal nerve probably contributed to the aspiration episode causing the death of our first patient, because the dissection of the mediastinum was difficult owing to the obliteration of the tissue planes caused by the first operation.

Our current technique evolved in parallel with our increasing understanding of the anomaly. We now believe that if the vascular compression is still evident on bronchoscopic examination after division of the ligamentum arteriosum and wide mobilization, aortic uncrossing should be performed early, thus minimizing the risk of damage to structures such as the recurrent laryngeal or phrenic nerves or the thoracic duct.

The group 2 patients had compressive symptoms mandating endotracheal intubation within 3 days of birth. Patient 4 had an enlarged, dextroposed ascending aorta, a right-sided aortic arch, and a rightsided descending aorta. The space normally occupied by the right main bronchus was narrow, accounting for the appearance of his symptoms in the neonatal period. In his case, posterior aortopexy allowed just enough space to relieve the bronchial compression. Postoperative ventilatory support was prolonged as a consequence of bronchopulmonary dysplasia related to prematurity. His airway, however, recovered completely, and at the time of his cardiac operation he had normal bronchoscopic findings. In recent years, we have successfully used tracheal stents in patients who had severe secondary tracheomalacia. This has allowed earlier extubation after the surgical intervention directed at relieving the compressive symptoms.

Patient 5 had compression of the left bronchus caused by a posterior and rightward displacement of the ascending aorta, in the context of agenesis of the right pulmonary artery and ventricular septal defects. She underwent division of a patent ductus arteriosus and freeing of the left bronchus. Bronchoscopic examination in the immediate postoperative period confirmed the relief of the vascular compression, with residual severe bronchomalacia. The subsequent right pneumonectomy accentuated the posterior and rightward displacement of the ascending aorta, for a second bronchoscopic study 2 months after pneumonectomy showed recurrent vascular compression. Compression of the distal trachea and left main bronchus in children with a shift of the mediastinum to the right owing to right lung hypoplasia or after right pneumonectomy has been described in reports by Dohlemann, ${ }^{23}$ Horvath ${ }^{24}$ Szarnicky, ${ }^{25}$ and their associaates. Rerouting of the aorta with a synthetic graft, as used by Horvath's group, ${ }^{23}$ was not considered to be a satisfactory solution in this patient with bronchomalacia and infection.

Selective left bronchial intubation, although initially successful in relieving the obstruction, was ultimately deleterious, because it caused the development of an aortobronchial fistula. A bronchoplastic procedure could perhaps have been considered. However, the risk of failure would have been high in a patient after a right pneumonectomy, with a long segment of bronchomalacia. ${ }^{26}$

Although patient 5 had two ventricular septal defects, which could incriminate a left-to-right shunt as a causative mechanism for her airway compression, she in fact began having symptoms immediately after birth, while having an elevated pulmonary vascular resistance and minimal left-to-right shunting. Thus we believe that the two group 2 patients, at first sight so different in their anomalies and pulmonary blood flow characteristics, share the cause of their bronchial compression: a mechanical obstruction by an enlarged, displaced ascending aorta. Aortopexy, not performed for the described reasons in patient 5 , should accompany the liberation of the bronchus.

The three group 3 patients present an interesting late complication after the arterial switch operation. Worsey and coworkers ${ }^{12}$ described this complication 
in a patient who had stridor 3 months after an arterial switch operation. Our patients' symptoms developed in a similar time frame, between 1 and 4 months after the operation.

We agree with Worsey's group ${ }^{12}$ that the posterior displacement of the ascending aorta after the Lecompte maneuver must play an important role in causing bronchial compression, but other mechanisms must contribute as well, because the condition appears to be uncommon and becomes manifest later, once fibrous tissue forms around the area of division of the patent ductus arteriosus. Airway obstruction then sets the scene for repeated infective episodes, which cause regional lymph node enlargement.

In all our patients, three distinct layers contributed to bronchial compression: the layer of lymph nodes, the scar tissue around the stump of the patent ductus arteriosus, and on a deeper plane the aortic "pincer."

Considering the large number of arterial switch operations performed worldwide, this complication seems rare. In our own series, we recognized it only three times in more than 800 cases. However, inasmuch as respiratory symptoms are common in this age group, their connection to the heart operation may not be realized. We could not find any particular pattern to identify the patients at risk for this condition and therefore cannot make any recommendations to try to avoid it.

On the basis of our experience, we chose to perform an extensive freeing of the bronchus to relieve the already symptomatic obstruction. Aortopexy was used as an adjunctive measure in patient 8 , the only one to have residual problems.

\section{Summary}

Three rare patterns of bronchovascular compression occurring in a young group of patients are described. Bronchoscopy was found to be the most useful diagnostic tool. The special pathologic problems posed by some of these patients led us to develop new surgical solutions. Bronchoplastic procedures were not used in this series, although at least five patients had significant secondary bronchomalacia. Because bronchomalacia affected relatively long bronchial segments in these small infants, we did not believe that the success of these procedures could be assured. An expectant policy of postoperative ventilation was used, and we successfully extubated all but one, who died of a complication related to a bronchial stent. When respiratory obstruction persists or recurs after the operation in this context, we think that vascular compression has to be carefully excluded.

\section{REFERENCES}

1. Sano S, Brawn WJ, Mee RB. Repair of truncus arteriosus and interrupted aortic arch. J Card Surg 1990;5:157-62.

2. Leijala $M$, Sairanen $H$, Maklinen L, Manuksela EL, Louihimo I. Iatrogenic, unexpected and other vascular rings in children. Eur J Cardiothorac Surg 1989;57:125-9.

3. Stanger P, Lucas RV, Edwards JE. Anatomic factors causing respiratory distress in acyanotic congenital heart disease. Pediatrics 1969;43:760-9.

4. Hordof AJ, Mellins RB, Gersony WM, Steeg CN. Reversibility of chronic obstructive lung disease in infancy following repair of ventricular septal defect. J Pediatr 1977;90:187-91.

5. Planche C, Lacour-Gayet F. Aortic uncrossing for compressive circumflex aorta: 3 cases. Presse Med 1984;13:1331-2 (in French).

6. Bruniaux J, Villain E, Sidi D, Almagne $C$, Kachaner $J$, Lecronier $G$, et al. Severe tracheo-bronchial compression due to encircling right aortic arch. Arch Mal Coeur 1984;7: 557-63 (in French).

7. Langlois J, Binet JP, DeBrux JL, Hvass V, Planche C. Aortic arch anomalies. In: Current topics in general thoracic surgery. New York: Elsevier, 1991:172-88.

8. Knight L, Edwards JE. Right aortic arch: types and associated cardiac anomalies. Circulation 1974;50;1047-51.

9. Hommel: Cited by Poynter CWM. Arterial anomalies pertaining to aortic arches and branches arising from them. Lincoln Studies (Lincoln, NE) 1916;16:221.

10. Gross RE. Surgical relief for tracheal obstruction by a vascular ring. N Engl J Med 1945;233:586-90.

11. Edwards JE. Anomalies of the derivatives of the aortic arch system. Med Clin North Am 1948;3:925.

12. Worsey J, Sim P, Newman B, DelNido P. Left main bronchus compression after arterial switch for transposition. Ann Thorac Surg 1994;57:1320-2.

13. Binet JP, Langlois J. Aortic arch anomalies in children and infants. J Thorac Cardiovasc Surg 1977;73:248-52.

14. Ergin MA, Jayaram N, LaCorte M. Left aortic arch and right descending aorta: diagnostic and therapeutic implications of a rare type of vascular ring. Ann Thorac Surg 1981;1:82-5.

15. Corno A, Giamberti A, Giannico S, Marino B, Rossi E, Marcelletti $\mathrm{C}$, et al. Airway obstructions associated with congenital heart disease in infancy. J Thorac Cardiovasc Surg 1990;99:1091-8.

16. Azarow KS, Pearl RH, Hoffman MA, Zurcher R, Edwards $\mathrm{FH}$, Cohen AJ. Vascular ring: Does magnetic resonance imaging replace angiography? Ann Thorac Surg 1992;53: 882-5.

17. D'Cruz IA, Cantez T, Namin EP, Licata R, Hastreiter AR. Right-sided aorta. Br Heart J 1966;28:722-39.

18. Backer CL, Ilbawi MN, Idriss FS, DeLeon SY. Vascular anomalies causing tracheoesophageal compression. J Thorac Cardiovase Surg 1989;97:725-31.

19. Van Son JA, Julsrud PR, Hagler DJ, Sim EKW, Pairolero PC, Puga FJ, et al. Surgical treatment of vascular rings: the Mayo Clinic experience. Mayo Clin Proc 1993;68:1056-63. 
20. Lam CR, Kabbani S, Arciniegas E. Symptomatic anomalies of the aortic arch. Surg Gynecol Obstet 1978;147:673-81.

21. Domalain MN, Jundt S, Braun P, Beaufils F, Narcy P, Gallet J-P. Pseudotracheomalacia and an unusual aortic arch. Ann Pediatr 1976;23:689-94.

22. Hellebrand WE, Kelley MJ, Talner NS, Stansel HC, Berman MA. Cervical aortic arch with retroesophageal aortic obstruction: report of a case and ssuccessful surgical intervention. Ann Thorac Surg 1978;1:86-92.

23. Dohlemann C, Mantel K, Schneider K, Guntner M, Kreutzer E, Hecker WC. Deviated trachea in hypoplasia and aplasia of the right lung: airway obstruction and its release by aortopexy. J Pediatr Surg 1990;25:290-3.

24. Horvath P, Dinwiddie R, Starck J. Succesful surgical treatment of tracheal compression following right pneumonectomy in infancy. Eur J Cardiothorac Surg 1990;4:351-4.

25. Szarnicki R, Mauseth K, de Leval M, Starck J. Tracheal compression by the aortic arch following right pneumonectomy in infancy. Ann Thorac Surg 1987;25:232-5.

26. Delorimer AA, Harrison MR, Hardy K, Howell LJ, Adzick NS. Tracheobronchial obstruction in infants and children. Ann Surg 1990;212:277-89. 